Case Report

\title{
Concurrent Spontaneous Sublingual and Intramural Small Bowel Hematoma due to Warfarin Use
}

\author{
Gül Pamukçu Günaydın, ${ }^{1}$ Hatice Duygu Çiftçi Sivri, ${ }^{1}$ Serkan Sivri, ${ }^{2}$ Yavuz Otal, ${ }^{1}$ \\ Ayhan Özhasenekler, ${ }^{3}$ and Gülhan Kurtoğlu Çelik ${ }^{1}$ \\ ${ }^{1}$ Department of Emergency Medicine, Ankara Atatürk Training and Research Hospital, Çankaya, 06800 Ankara, Turkey \\ ${ }^{2}$ Department of Cardiology, Ankara Atatürk Training and Research Hospital, Çankaya, 06800 Ankara, Turkey \\ ${ }^{3}$ Department of Emergency Medicine, Faculty of Medicine, Yıldirım Beyazıt University, Çankaya, Ankara, Turkey
}

Correspondence should be addressed to Gül Pamukçu Günaydın; gulpamukcu@gmail.com

Received 3 September 2015; Accepted 19 October 2015

Academic Editor: Kalpesh Jani

Copyright (C) 2015 Gül Pamukçu Günaydın et al. This is an open access article distributed under the Creative Commons Attribution License, which permits unrestricted use, distribution, and reproduction in any medium, provided the original work is properly cited.

Introduction. We present a case of concurrent spontaneous sublingual and intramural small bowel hematoma due to warfarin anticoagulation. Case. A 71-year-old man presented to the emergency department complaining of a swollen, painful tongue. He was on warfarin therapy. Physical examination revealed sublingual hematoma. His international normalized ratio was 11.9. The computed tomography scan of the neck demonstrated sublingual hematoma. He was admitted to emergency department observation unit, monitored closely; anticoagulation was reversed with fresh frozen plasma and vitamin K. 26 hours after his arrival to the emergency department, his abdominal pain and melena started. His abdomen tomography demonstrated intestinal submucosal hemorrhage in the ileum. He was admitted to surgical floor, monitored closely, and discharged on day 4. Conclusion. Since the patient did not have airway compromise holding anticoagulant, reversing anticoagulation, close monitoring and observation were enough for management of both sublingual and spontaneous intramural small bowel hematoma.

\section{Introduction}

Sublingual hematoma is a rare and potentially life threatening complication of oral anticoagulation [1-3]. Spontaneous intramural small bowel hematoma (SISBH) due to oral anticoagulation is also rare but generally is not life threatening and may improve with medical treatment [4].

We present the case of concurrent spontaneous sublingual and intramural small bowel hematoma due to warfarin anticoagulation. To our knowledge, there is only one published case in Google scholar and none in PubMed that these two entities are seen together.

\section{Case}

A 71-year-old man presented to the emergency department complaining of a swollen, painful tongue and difficulty to speak that began a few hours ago. He did not have recent trauma, dental work, cough, or fever. He was on warfarin therapy, $5 \mathrm{mg}$ /day for recurrent deep vein thrombosis for over a year.

His vital signs were within normal limits. Oral physical examination revealed $3 \times 3 \mathrm{~cm}$ sized, red-purple, tense, and tender mass consistent with a sublingual hematoma (Figure 1). He was not in respiratory distress and did not have stridor. The submental triangle was swollen and ecchymotic (Figure 2).

Laboratory studies were significant for international normalized ratio (INR) of $11.9(0.8-1.2)$, with a prothrombin time (PT) of $139.1 \mathrm{sec}(8.8-14)$, and with partial thromboplastin time (PTT) of $108.7 \mathrm{sec}(22-38)$. He said that his INR levels were not checked for over 6 months because he was living in a remote village that was 2 hours away from the nearest hospital that has the test. His hemoglobin was $14.2 \mathrm{~g} / \mathrm{dL}$, platelet count was $234 \mathrm{~K} / \mu \mathrm{L}$, and white blood cell count was $15.7 \mathrm{~K} / \mu \mathrm{L}$. His electrolytes, liver function tests, urea, and creatine levels were within normal limits. The computed tomography scan of the neck demonstrated sublingual hematoma. 


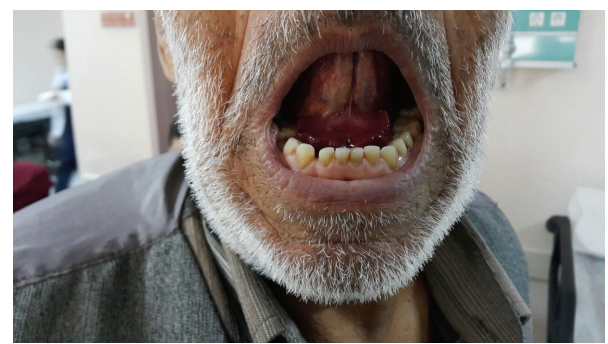

FIGURE 1: Sublingual hematoma.

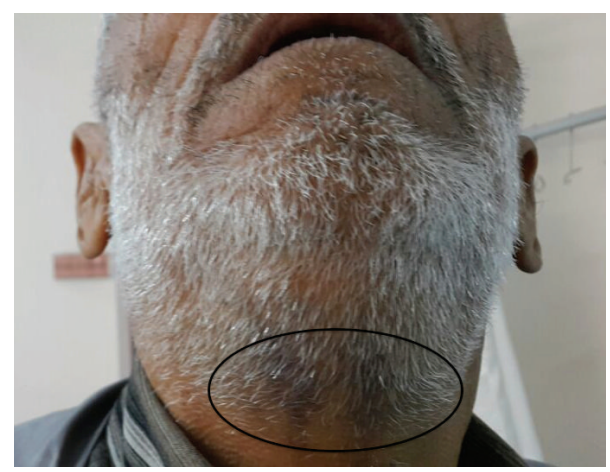

Figure 2: Submental ecchymosis.

The patient was evaluated by otolaryngologist. Flexible nasopharyngoscopy demonstrated that the hematoma was limited to the sublingual area. We stopped warfarin treatment and coagulopathy was reversed with $10 \mathrm{mg}$ of IV vitamin $\mathrm{K}$ and 5 units of fresh frozen plasma. An INR measurement was 1.4 after 3 hours. He was given fentanyl for pain reduction.

26 hours after his arrival to the emergency department, his abdominal pain and melena started. Abdominal ultrasound revealed mural thickening in the intestinal wall. His abdomen tomography demonstrated intestinal submucosal hemorrhage in the ileum (Figure 3).

The patient was evaluated by general surgeon and was admitted. He was monitored closely and kept nothing by mouth. He was started on IV fluids and omeprazole. His hematocrit remained stable, and both sublingual and intestinal hemorrhage resolved slowly. He was started on oral diet on day 3 and discharged on day 4 .

\section{Discussion}

Bleeding is the main complication of anticoagulation [5]. The incidence of hemorrhage is related to INR level [1]. Our patient had elevated INR level possibly due to not being regularly checked since he was living in village far away from the hospital.

Upper airway hematomas are rare. Retropharyngeal, submaxillary and epiglottic hematomas may be difficult to diagnose, but sublingual hematoma can be seen easily [2]. Computed tomography of the upper airway is needed to define the extent of hemorrhage $[6,7]$. In our patient physical

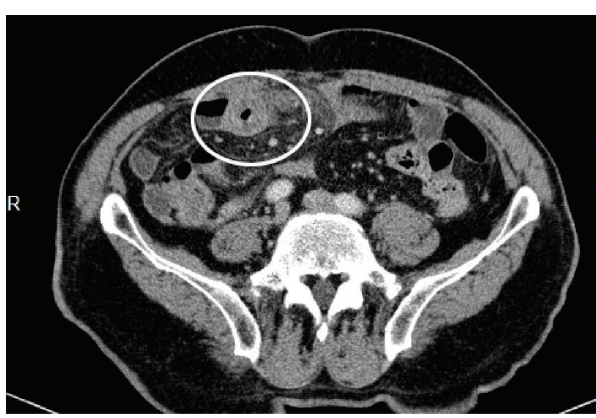

FIGURE 3: Intestinal submucosal hemorrhage.

exam revealed sublingual hematoma. CT was obtained to see the extent of hemorrhage.

Sublingual hematoma may be life threatening by causing airway obstruction. Some authors recommend that medical treatment combined with early prophylactic surgical airway should be standard of care but there is no consensus [8]. Surgical decompression of the hematoma is a treatment choice but it may cause edema, airway obstruction, and massive bleeding [9]. Awake fiber optic nasotracheal intubation is a good option for securing the airway; it can also show the extension of hemorrhage into other areas of upper airway [8]. Since the patient did not have airway compromise he was observed conservatively and we did not perform surgery or early intubation or surgical airway.

Medical treatment of overanticoagulation is withholding the drug, parenteral vitamin $\mathrm{K}$ and fresh frozen plasma or factor concentrates $[1,2,10]$. Some researchers recommend the use of antibiotics in the treatment of upper airway hematomas because it may be a result of localized infection and vasodilatation [1] but our patient did not have any symptoms of infection and antibiotics were not necessary. The use of systemic steroids is controversial and not of proven benefit in upper airway hematomas [1]; we did not use steroids.

The clinical presentation of SISBH depends on the location and extent of the hematoma. Acute abdominal pain and ileus symptoms in patient on anticoagulation treatment should raise suspicion. USG may show intramural bowel hematomas but its sensitivity is less than CT [11]. CT may show circumferential bowel wall thickening, intramural hyper density, luminal narrowing, and intestinal obstruction. In our patient the diagnosis was made with USG and CT was obtained to see the exact location and extent of hematoma.

Holding anticoagulant, reversing anticoagulation, close monitoring and observation will be enough in management of most SISBH cases [11]. Surgery should be reserved for cases with uncertain diagnosis or complications like intraabdominal hemorrhage, perforation, peritonitis, and intestinal obstruction not responding to conservative treatment [12]. Our patient was monitored closely and reversal of anticoagulation was enough for successful treatment. Since melena was self-limited and it was not accompanied by hematemesis we think it may be due to the penetration of the intestinal hematoma that eventually healed by supportive treatment. 


\section{Conflict of Interests}

The authors have no conflict of interests to declare.

\section{Acknowledgments}

The work should be attributed to Ankara Atatürk Training and Research Hospital, Department Of Emergency Medicine and Department Of Emergency Medicine, Faculty Of Medicine, Yıldırım Beyazıt University.

\section{References}

[1] D. C. Bloom, T. Haegen, and M. A. Keefe, "Anticoagulation and spontaneous retropharyngeal hematoma," Journal of Emergency Medicine, vol. 24, no. 4, pp. 389-394, 2003.

[2] R. González-García, G. Schoendorff, M. F. Muñoz-Guerra, F. J. Rodríguez-Campo, L. Naval-Gías, and J. Sastre-Pérez, "Upper airway obstruction by sublingual hematoma: a complication of anticoagulation therapy with acenocoumarol," American Journal of Otolaryngology-Head and Neck Medicine and Surgery, vol. 27, no. 2, pp. 129-132, 2006.

[3] M. Buyuklu, E. M. Bakirci, E. Topal, and G. Ceyhun, "Spontaneous lingual and sublingual haematoma: a rare complication of warfarin use," BMJ Case Reports, 2014.

[4] F. Altintoprak, E. Dikicier, M. Akyüz et al., "A retrospective review of patients with non-traumatic spontaneous intramural hematoma," Turkish Journal of Gastroenterology, vol. 24, no. 5, pp. 392-399, 2013.

[5] S. Parvizi, S. Mackeith, and M. Draper, "A rare cause of upper airway obstruction: spontaneous synchronous sublingual and laryngeal haematomas," BMJ Case Reports, 2011.

[6] W. J. Frohna, R. C. Lowery Jr., and F. Pita, "Lingual and sublingual hematoma causing upper airway obstruction," Journal of Emergency Medicine, vol. 43, no. 6, pp. 1075-1076, 2012.

[7] R. E. Berthelsen, S. Tadbiri, and C. V. Rosenstock, "Spontaneous sublingual haematoma in a patient treated with warfarin," Acta Anaesthesiologica Scandinavica, vol. 57, no. 4, pp. 530-531, 2013.

[8] A. F. Cohen and S. P. Warman, "Upper airway obstruction secondary to warfarin-induced sublingual hematoma," Archives of Otolaryngology-Head and Neck Surgery, vol. 115, no. 6, pp. 718-720, 1989.

[9] E. Brotfain, L. Koyfman, S. Andrey et al., "Spontaneous sublingual hematoma: surgical or non-surgical management?" International Journal of Case Reports and Images, vol. 3, no. 1, pp. 1-4, 2012.

[10] E. Cashman, M. Shandilya, M. Amin, J. Hughes, and M. Walsh, "Warfarin-induced sublingual hematoma mimicking ludwig angina: conservative management of a potentially lifethreatening condition," Ear, Nose \& Throat Journal, vol. 90, no. 2, article E1, 2011.

[11] M. Moftah, R. Cahill, and S. Johnston, "Spontaneous sublingual and intramural small-bowel hematoma in a patient on oral anticoagulation," Gastroenterology Insights, vol. 4, no. 2, article e17, 2012.

[12] A. Abdel Samie, R. Sun, A. Huber, W. Höpfner, and L. Theilmann, "Spontaneous intramural small-bowel hematoma secondary to anticoagulant therapy: a case series," Medizinische Klinik-Intensivmedizin und Notfallmedizin, vol. 108, no. 2, pp. 144-148, 2013. 


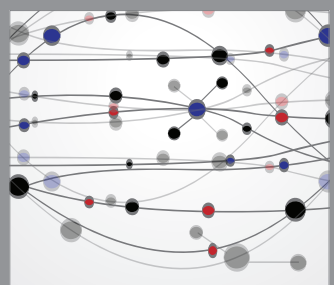

The Scientific World Journal
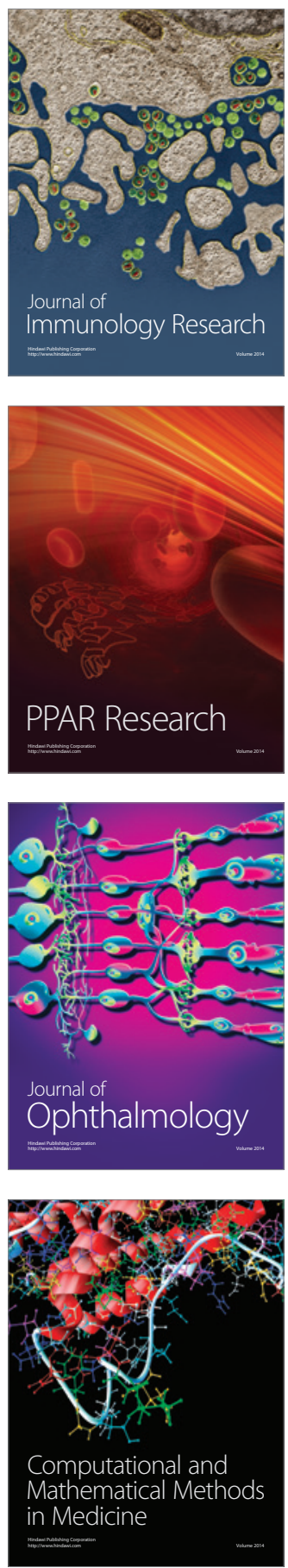

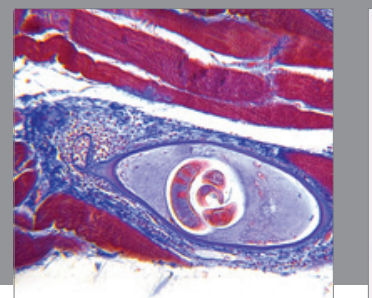

Gastroenterology

Research and Practice
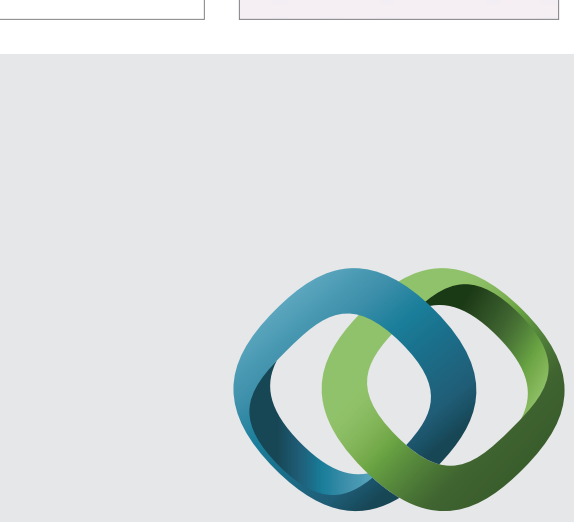

\section{Hindawi}

Submit your manuscripts at

http://www.hindawi.com
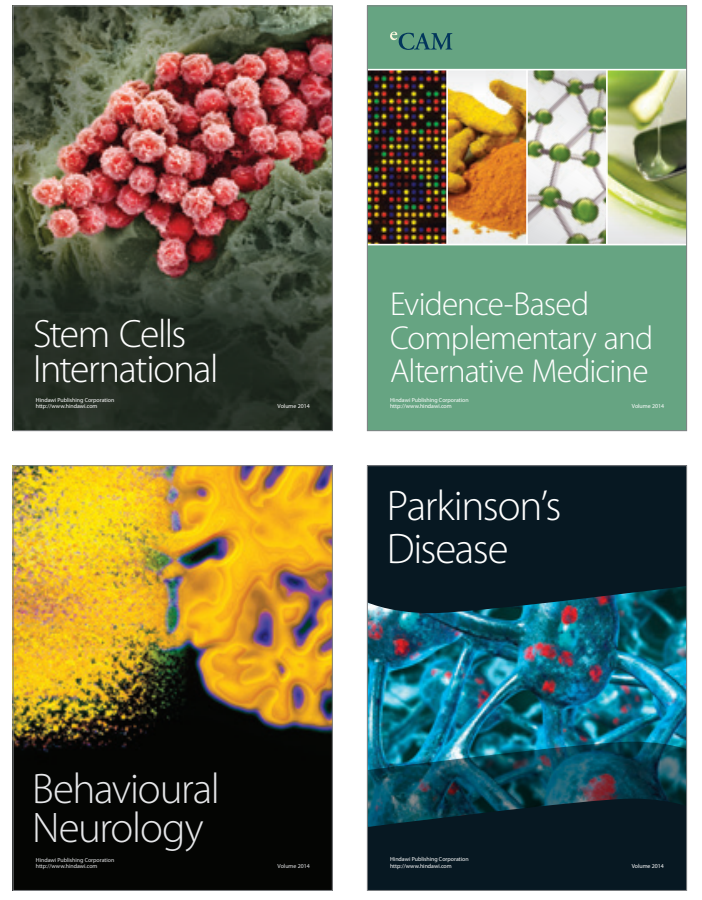
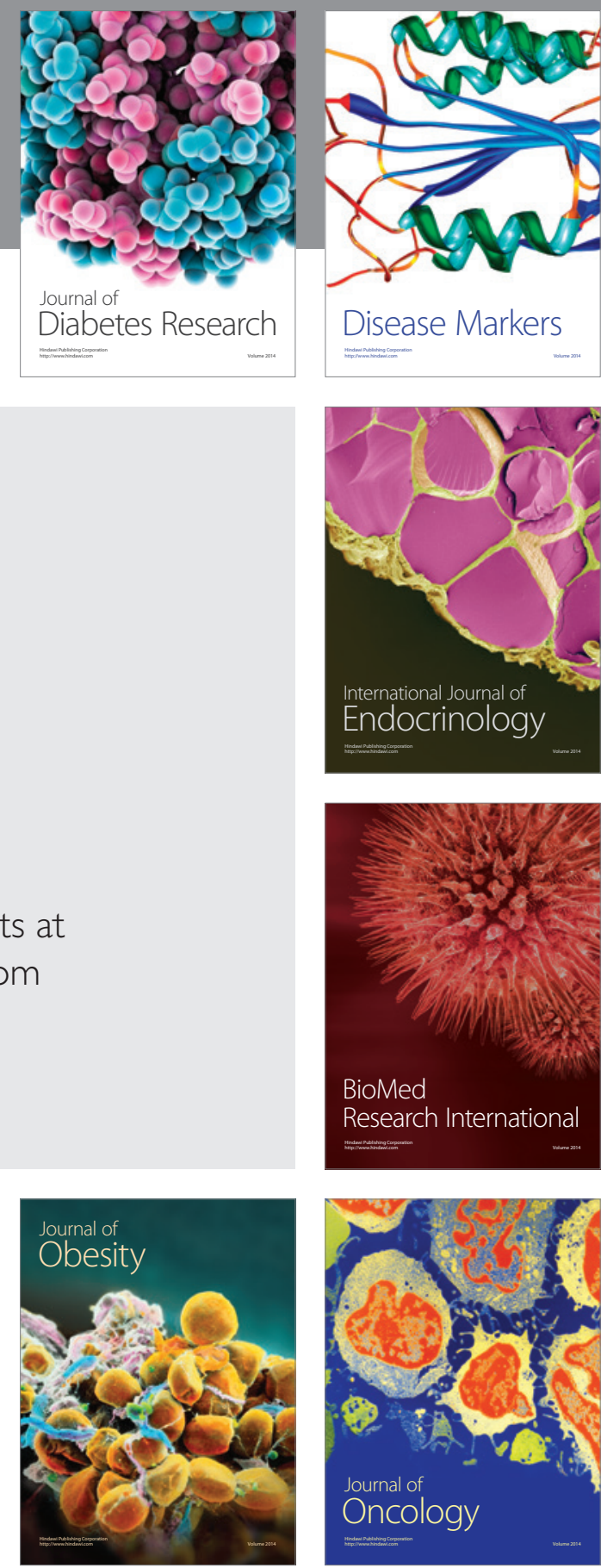

Disease Markers
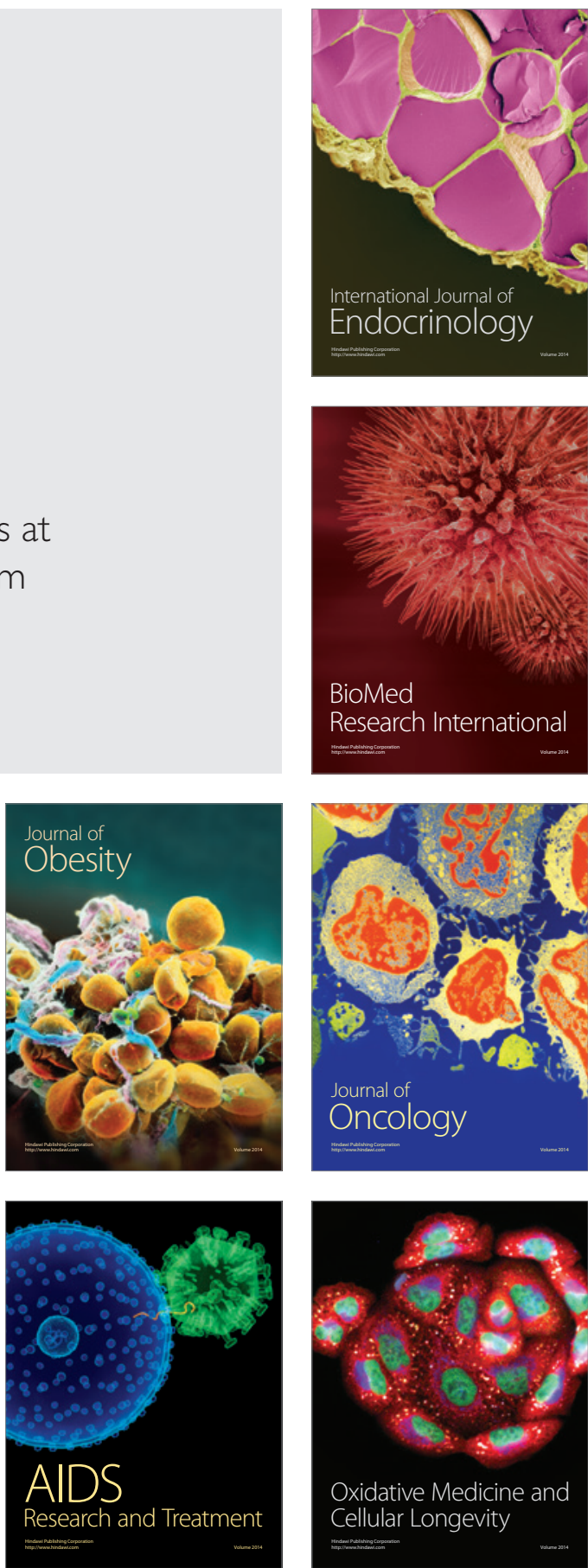